\title{
Endoscopic resection of a rectal gastrointestinal stromal tumor using the submucosal tunneling endoscopic resection (STER) technique
}

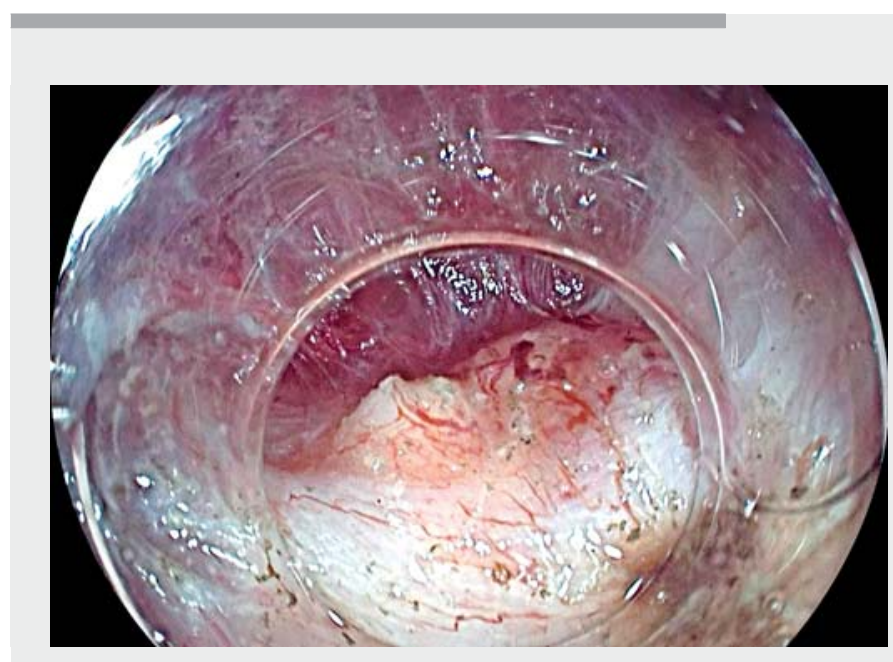

Video 1 Endoscopic resection of a rectal gastrointestinal stromal tumor using the submucosal tunneling endoscopic resection (STER) technique.

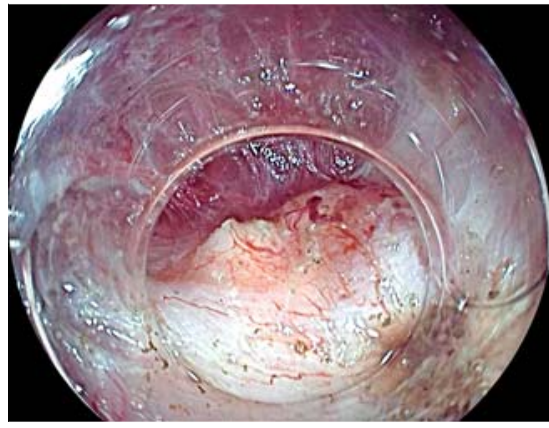

- Fig. 1 Endoscopic view during submucosal tunneling endoscopic resection (STER) of a rectal gastrointestinal stromal tumor, which allows an interesting exposure of the lesion within the tunnel, particularly while making the muscular incision in the healthy margin.

The optimal treatment for a gastrointestinal stromal tumor (GIST) of the rectum is controversial owing to its extremely low incidence [1]. The submucosal tunneling endoscopic resection (STER) technique is a so-called "nonexposed" fullthickness endoscopic resection technique developed to remove upper gastrointestinal submucosal tumors (SMTs) arising from the muscularis propria [2,
3]. This technique allows a very interesting exposure of a GIST, as the axis of the knife is more tangential than when using an "exposed ESD technique", which features a perpendicular axis that carries a risk of $\mathrm{R} 1$ resection. We believe that it could also be interesting for the resection of rectal SMTs. We report here the first successful use of this technique, with an accompanying video ( $\downarrow$ Video 1 ), for the removal of a $15-\mathrm{mm}$ rectal GIST.

A 59-year-old woman was referred for endoscopic resection of a lower rectal SMT. The lesion had been discovered incidentally during a screening colonoscopy. Endoscopic ultrasound confirmed a rectal SMT arising from the muscularis propria. The STER procedure was performed using a DualKnife, starting the submucosal tunnel $3 \mathrm{~cm}$ upstream of the lesion. After releasing the submucosa around the tumor within this tunnel, we made a circumferential muscular incision in the healthy margin (> Fig.1). We then carried out complete enucleation, while preserving the external muscular layer. The lesion was removed from the submucosal tunnel using tripod forceps. The tunnel entrance was closed with five 16-mm clips.

Histopathological analysis showed complete resection of a $15-\mathrm{mm}$ GIST, with a mitotic index of 14 mitoses per $5 \mathrm{~mm}^{2}$, corresponding to a lesion at high risk of recurrence [4]. Molecular analysis showed the presence of a KIT exon 1 mutation. A multidisciplinary consultation meeting proposed giving an adjuvant treatment with imatinib [5].

The STER technique seems feasible in the rectum and helpful to facilitate complete R0 resection of rectal GISTs. This technique allows an interesting exposure of the GIST, particularly while making the muscular incision in the healthy margin.

Endoscopy_UCTN_Code_TTT_1AO_2AG

\section{Competing interests}

The authors declare that they have no conflict of interest.

The authors

Timothée Wallenhorst ${ }^{1}$, Jérémie Jacques ${ }^{2}$, Astrid Lièvre ${ }^{1}$, Mael Pagenault ${ }^{1}$, Guillaume Bouguen ${ }^{1}$, Mathieu Pioche ${ }^{3}$, Charlène Brochard ${ }^{1}$

1 Department of Endoscopy and Gastroenterology, Centre Hospitalier Universitaire Pontchaillou, Rennes, France

2 Department of Hepatogastroenterology, Centre Hospitalier Universitaire Dupuytren, Limoges, France

3 Department of Gastroenterology, Hôpital Edouard Herriot, Hospices Civils de Lyon, Lyon, France

\section{Corresponding author}

Timothée Wallenhorst, MD

Service des Maladies de l'Appareil Digestif, CHU Pontchaillou, 35033 Rennes Cedex 9,

France

timothee.wallenhorst@chu-rennes.fr 


\section{References}

[1] Shu P, Sun XF, Fang Y et al. Clinical outcomes of different therapeutic modalities for rectal gastrointestinal stromal tumor: Summary of 14-year clinical experience in a single center. Int J Surg 2020; 77: 1-7

[2] ASGE Technology Committee, Aslanian HR, Sethi A et al. ASGE guideline for endoscopic full-thickness resection and submucosal tunnel endoscopic resection. VideoGIE 2019; 4: 343-350

[3] Du C, Chai NL, Ling-Hu EQ et al. Submucosal tunneling endoscopic resection: An effective and safe therapy for upper gastrointestinal submucosal tumors originating from the muscularis propria layer. World J Gastroenterol 2019; 25: 245-257
[4] Joensuu H. Risk stratification of patients diagnosed with gastrointestinal stromal tumor. Hum Pathol 2008; 39: 1411-1419

[5] Landi B, Blay JY, Bonvalot S et al. Gastrointestinal stromal tumours (GISTs): French Intergroup Clinical Practice Guidelines for diagnosis, treatments and follow-up. Dig Liver Dis 2019; 51: 1223-1231

Bibliography

Endoscopy 2022; 54: E273-E274

DOI 10.1055/a-1508-5241

ISSN 0013-726X

published online 18.6.2021

(C) 2021. Thieme. All rights reserved.

Georg Thieme Verlag KG, Rüdigerstraße 14, 70469 Stuttgart, Germany
ENDOSCOPY E-VIDEOS

https://eref.thieme.de/e-videos

口居 Endoscopy E-Videos is an open access online section, 回: reporting on interesting cases and new techniques in gastroenterological endoscopy. All papers include a high quality video and all contributions are freely accessible online. Processing charges apply (currently EUR 375), discounts and wavers acc. to HINARI are available.

This section has its own submission website at

https://mc.manuscriptcentral.com/e-videos 